\title{
BALANCE DE LOS ESTUDIOS CULTURALES EN AMÉRICA LATINA. LA RUTA DE LA COMUNICACIÓN EN LA DEFINICIÓN DE OBJETO
}

\author{
Valeria Fernández Hasan ${ }^{1}$ \\ Universidad Nacional de Cuyo, CONICET- Argentina
}

\begin{abstract}
Resumen: Este estudio analiza el derrotero de los Estudios Culturales Latinoamericanos en Comunicación desde un punto de vista situado (Haraway, 1993). Es una tarea ardua y, al mismo tiempo, una especie de pendiente al que no puede ni debe esquivársele. Una tarea ardua porque la producción relativa a Estudios Culturales o Cultural Studies ha sido profusa a lo largo de los últimos 20 años y el recorte para el caso de la Comunicación requiere una atención diferencial. Los debates en torno de los Estudios Culturales (EC) no son novedad y de lo que trataremos aquí es de establecer su objeto, sus diferencias geográficas más importantes y su propuesta para el caso del campo disciplinar de la Comunicación. Finalmente, una especie de pendiente al que no puede ni debe esquivársele, ya que los problemas de definición de objeto al interior de la disciplina continúan teniendo vigencia y los EC han tenido durante estas dos últimas décadas una influencia importante en este asunto. En síntesis, intentaremos trazar un mapa de los EC latinoamericanos, algunos/as de sus referentes más citados, sus propuestas más importantes, sus legados, su especificidad en el campo de la Comunicación y su estado actual para, sobre el final, esbozar una propuesta acerca del objeto teórico de la Comunicología.
\end{abstract}

Palabras clave: estudios culturales, comunicación, cultura, medios de comunicación

Abstract: This study analyzes the course of the Cultural Latin-American Studies in Communication from a placed point of view (Haraway, 1993). It is an arduous task and, at the same time, a species of earring to the one that neither can him must not even withdraw. An arduous task because the production relative to Cultural Studies has been profuse throughout last 20 years and the cut for the specific case of the Communication needs a differential attention. The debates around the Cultural Studies (CS) are not an innovation and of what we will treat here it is of establishing his object, his more important geographical differences and his offer for the case of the field to discipline of the Communication. Finally, a species of earring to the one that neither can him must not even withdraw, since the problems of definition of object to the inside of the discipline continue having force and the CS have had during these last two decades an important influence in this matter. In synthesis, we will try to plan a map of the Latin-American CS, some of his more mentioned modals, his more important offers, his legacies, his specificity in the field of the Communication and his current condition for, by the end, to outline an offer it brings over of the theoretical object of the Comunicology.

Keywords: cultural studies, ommunication, culture, mass media

\section{Derrotero histórico. Constitución del campo y proceso de institucionalización de los EC en América Latina}

Un análisis del derrotero de los EC en América Latina no puede soslayar un intento de reconstrucción histórica de cómo fue que los EC arribaron a nuestro continente y cómo fue, si es que fue, realizada su adaptación a las particularidades de la región. En este sentido, la brasilera Ana Escosteguy

1 Doctora en Ciencias Sociales con línea de investigación en género y medios de comunicación. Investigadora del INCIHUSA-CONICET- Argentina. Docente e investigadora de la Universidad Nacional de Cuyo. 
resalta que una de las marcas básicas de los EC es "la importancia dada al contexto donde ocurre la acción social, el foco localizado e históricamente específico, la atención dada a las especificidades y particularidades articuladas a una coyuntura histórica determinada, produciendo una teoría sustentada en las diferencias culturales" (Escosteguy, 2002: 35). Veremos en lo que sigue en qué medida esto fue posible e incluso intentaremos dilucidar si fue una meta a alcanzar en todos los casos.

En la misma línea que lo plantea Escosteguy, la teórica culturalista Nelly Richard relata que lo primero que caracterizó a los $E^{2}$ fue su voluntad de democratizar el conocimiento y de pluralizar las fronteras de la autoridad académica, propiciando la entrada a saberes que la jerarquía universitaria suele discriminar por impuros en cuanto se rozan, conflictivamente, con el fuera de corpus de ciertos bordes llamados cultura popular, movimientos sociales, crítica feminista, grupos subalternos. En este sentido ella sostiene que la conflictualidad política e ideológica del saber de los EC merece ser reafirmada contra el modelo de trascendencia filosófica de la universidad moderna que históricamente ha intentado separarse del contexto en el que está inserta, alejando lo académico de la contingencia social y política (Richard, 2005).

Una vez traspasado el Atlántico, en EEUU, una de las formas que los EC tienen de manifestar su compromiso con las luchas de la sociedad civil, consistió en defender a diversos grupos de identidad mediante activas políticas de representación reinterpretando, universitariamente, los derechos de estos grupos a intervenir en los sistemas académicos de conocimiento para transformar sus reglas. Según Richard, no cabe duda de que las luchas antidiscriminatorias que promueven la inserción de los grupos minoritarios en diferentes estructuras públicas tales como la universitaria, ha obligado a una redefinición más amplia y flexible de los criterios de selección y valoración de las identidades culturales tradicionalmente fijadas por el aparato académico. Sin embargo, al mismo tiempo, el activismo de las políticas de representación de los grupos de identidad minoritarios (latinos, chicanos, negros, feministas, homosexuales, etcétera) también ha simplificado la cuestión de la identidad y de la representación, al someter generalmente a ambas a una tiranía de la ilustratividad que obliga a sus producciones de textos a la formulación monocorde de una condición de sujeto predeterminada (Richard, 2005). George Yúdice (2002) explica que en el marco de los Cultural Studies se juzga que algunas prácticas y expresiones culturales populares, especialmente la música y otras formas altamente tecnificadas como el cine o el video, tanto como las prácticas literarias más tradicionales (poesía, testimonio) cultivadas por las minorías raciales, tienen efectos subversivos contra el statu quo. Desde este punto de vista, señala el autor, las representaciones multiculturales suelen considerarse instrumentos viables para enfrentar los efectos de la discriminación. Sin embargo, la creciente importancia académica de los

\footnotetext{
${ }^{2}$ No voy a referirme aquí a los Cultural Studies británicos, fundados en 1964 en Birmingham por Raymond Williams, Richard Hoggart, Edward P. Thompson y Stuart Hall y que la mayoría de los teóricos norteamericanos, australianos y latinoamericanos que se reconocen como culturalistas identifican como sus antecesores y padres fundadores de una u otra manera. En orden a esta lógica, en este escrito, tomaré a la expansión de los EC británicos al resto del mundo (EEUU, Australia y América Latina) como el Big Bang de los EC, producido entre los años 80 y 90 .
} 
Cultural Studies se ha dado combinadamente con una pérdida de importancia de la condición política que era parte de su particularidad original. Su carácter político ha venido disolviéndose en una retórica de la política y los asuntos de poder que no permite ver las prácticas de los actores sociales (social agents) centrándose básicamente en el análisis de textos y discursos dejando de lado las prácticas sociales específicas (Mato, 2001).

Daniel Mato (2001) explica en la introducción al libro "Cultura y transformaciones sociales en tiempos de globalización" que en América Latina se produjo un proceso acelerado de institucionalización de lo que se denominó Estudios culturales latinoamericanos. Según el autor, este proceso ocurrió en diálogo, relación y como consecuencia del proceso de institucionalización de lo que en EEUU, Inglaterra y Australia llaman Cultural Studies y de lo denominan Latin American Cultural Studies.

Como se ha dicho y leído muchas veces, durante ese proceso de institucionalización, los autores y autoras latinoamericanos identificados con los estudios en cultura (Carlos Altamirano, Renato Ortiz, Beatriz Sarlo, etcétera), no se sentían representantes de los EC latinoamericanos, sino que declaraban ser parte de algo previo a ellos, "Estudios de Cultura y Poder", "Estudio de Cultura", "Sociología de la Cultura", "Análisis cultural". En opinión del propio Mato, lo que se hacía y aún se hace en América Latina encuentra antecedentes en los escritos y prácticas de intelectuales y artistas latinoamericanos junto a obras de intelectuales franceses, alemanes, italianos y estadounidenses. Mato niega que las prácticas intelectuales latinoamericanas sean puras o vírgenes de todo contacto con otras tradiciones intelectuales. Su propuesta consiste en tener conciencia tanto de las diferencias de contextos institucionales y sociales como de las de tradiciones intelectuales, para poder dialogar y apropiarse conciente y creativamente de todo aquello que se juzgue conveniente (Mato, 2001).

Por su lado, Richard señala que la moda de los EC habría ido borrando la densidad histórica de lo local y de sus "regionalismos críticos". Desde ese punto de vista, una posición común es la que argumenta que el referente hegemónico de los EC de alguna forma silencia o aplasta la tradición del ensayismo latinoamericano que anticipó varios de los actuales desplazamientos de fronteras disciplinarias que tanto se celebran internacionalmente. Otra de sus críticas tiene que ver con que la obstrucción de esa tradición y la negación de sus memorias en español se verían reforzadas por cómo el corpus de los textos culturales de la "descolonización" ha sido desplazado por la supremacía teórico-metropolitana del tema del "poscolonialismo" (Richard, 2005). Richard coincidirá con Mato en que la función-centro de la dominante académica norteamericana controla los nombres y las categorías de discurso que entran en circulación internacional y dota de legitimidad institucional a los términos de debate que ella misma clasifica y organiza de acuerdo a sus propias jerarquías conceptuales y políticoinstitucionales.

El proceso de institucionalización de los Cultural Studies es, entonces, de carácter transnacional. Para su análisis, los elementos concernientes a las relaciones de poder al interior de las instituciones académicas y los individuos no pueden dejarse de lado. En este sentido, en primer lugar, la expresión y 
publicación de ideas en inglés ejerce una fuerte influencia en la configuración del canon o campo. En segundo lugar, como el inglés marca un uso colonial de la lengua sobre el español-castellano o el portugués, de la misma manera, éstos dos últimos lo hacen sobre las lenguas indígenas de algunos/as intelectuales en países cuya población indígena representa una parte importante de las respectivas poblaciones nacionales, caso de Ecuador, Bolivia, Guatemala. En tercer lugar, aparece el hecho de que las prácticas académicas tienen a la escritura como principal medio en contraposición con otros medios utilizados por intelectuales fuera de la Academia como la oralidad presencial y/o diversos medios visuales, de audio y audiovisuales. El peso de la escritura en la definición del campo pareciera haber influenciado también en la denominación de Studies (Mato, 2001). En contraposición, uno de los procesos más necesitados de investigación en América Latina es aquel en el que se produce la profunda compenetración entre la oralidad que perdura como experiencia cultural primaria de las mayorías y la visualidad tecnológica, como oralidad secundaria según algunos/as autores/as, que tejen y organizan las gramáticas tecnoperceptivas de la radio y el cine, del video y la televisión. Las mayorías en América Latina se incorporan a, y se apropian de la modernidad sin dejar su cultura oral (desde los géneros y las narrativas, los lenguajes y los saberes, de la industria y la experiencia audiovisual). Según Martín Barbero, la complicidad entre oralidad y visualidad no remite a los exotismos de un analfabetismo tercermundista sino a "la persistencia de estratos profundos de la memoria y la mentalidad colectiva sacados a la superficie por las bruscas alteraciones del tejido tradicional que la propia aceleración modernizadora comporta" (G. Marramao) (Martín Barbero, 2000).

En pocas palabras, en el proceso de conformación del campo, las voces con mayor poder para establecer qué le es propio, temas, enfoques, autores, metodologías, etcétera, son las que se expresan mediante publicaciones en inglés ${ }^{3}$. Mato señala que se ha configurando un canon que aunque se exprese en varios idiomas básicamente se escribe en inglés, o que aún escrito en español o portugués, se produce en el contexto de las instituciones académicas de EEUU, Inglaterra y Australia y se legitima, circula y reproduce a través de las respectivas industrias editoriales y mercados de estudios de posgrado.

De acuerdo al estudio de Mato, la irrupción de la denominación "Estudios Culturales Latinoamericanos" en las universidades latinoamericanas ha sido consecuencia de entrecruzamientos entre las prácticas de académicos e intelectuales de América Latina con colegas, universidades, editoriales y revistas académicas de EEUU y Gran Bretaña. Lo positivo de esto sería para él

\footnotetext{
${ }^{3}$ De acuerdo con Mato, en el caso específico de los Latin American Cultural Studies (LACS), referidos específicamente al campo que se construye en inglés, la relación contexto/discurso es un asunto más complejo y a la vez más delicado políticamente que el de los Cultural Studies. Más complejo porque en la constitución del canon también participan intelectuales que hablan desde América Latina, o que son originarios de América Latina aunque producen desde instituciones académicas de países de habla inglesa. Y más delicado políticamente porque los LACS no sólo están conceptualmente vinculados a los Cultural Studies, sino también a los "Area Studies" (estudios de áreas o regiones del mundo): asociados a proyectos imperiales, a la producción de conocimientos para uso en las metrópolis acerca de pueblos y naciones dominadas, o que se proyecta dominar. Involucran a disciplinas como Historia, Ciencias Políticas, Sociología, Idiomas, Geografía, Literatura. En contraste con los EC, a menudo incluyen la diáspora y emigración de la zona estudiada.
} 
el debilitamiento de las rigideces disciplinares y del poder de las instituciones académicas que conforman el sistema científico favoreciendo así iniciativas transdisciplinarias. Del lado negativo, indica la sobrevaloración de las tendencias intelectuales de los centros y la vinculación a ellas, a la vez que la desestimulación o no estimulación a la vinculación con prácticas críticas en cultura y poder desarrolladas por intelectuales locales en una amplia diversidad de movimientos sociales y en otros ámbitos más allá de las universidades.

Para terminar, la posición de Mato respecto de la existencia de un campo al cual considerar como propio de los EC para el caso latinoamericano, éste no debiera incluir aquellas prácticas intelectuales que se apropian [...] de las líneas de trabajo (y bibliografía) inicialmente generadas por los intelectuales de Birmingham o sus seguidores en EEUU, Australia y Nueva Zelanda ya que ir por allí sería un ejercicio de importación a la manera de repetición de experiencias de colonización intelectual y política. La delimitación de un campo propio debiera incluir, según Mato, aquellas prácticas intelectuales de carácter no-disciplinario, o transdisciplinario, que estudian y/o intervienen reflexivamente en asuntos de cultura y política/poder, y que lo hacen en relación a condiciones contextuales y coyunturales específicas, cualquiera sea su genealogía intelectual, y/o su historia institucional. A esto Mato denomina Prácticas Intelectuales en Cultura y Poder (Mato, 2002). En este sentido, el argumento del autor tiene que ver con poner de relieve que si en América Latina existen "líneas/tradiciones de trabajo que trascienden/atraviesan las fronteras disciplinarias y que tienen aproximaciones políticas a lo cultural, y culturales a lo político, a veces con objetivos de intervención y por tanto contextualmente referidas, entonces puede resultar fértil valorarlas, revisarlas, criticarlas y profundizarlas de manera conciente. De este modo, antes que traducir literalmente el nombre EC y con ello asumir como referentes canónicos los que acompañan a esa traducción, la posición de Mato indica que es potencialmente más provechoso hacer un esfuerzo por recuperar creativamente los antecedentes de este campo en la historia intelectual de América Latina. Su propuesta es abandonar el uso de la expresión Estudios Culturales Latinoamericanos para adoptar la más pertinente Estudios Latinoamericanos sobre Cultura y Poder, para poner de relieve las tradiciones latinoamericanas de intelectuales políticamente comprometidos y también para prevenir ante la despolitización que crecientemente se observa en algunas variantes de los Cultural Studies que se hacen en inglés.

Nelly Richard señala que el caso de los EC en América Latina resulta una especie de representación de una otredad que el dispositivo metropolitano de codificación académica convierte en fetiche romántico-popular de su discurso sobre marginalidades y periferias culturales. "Se organiza un complejo juego de reconocimientos y desconocimientos que lleva la "función-centro" de la teoría metropolitana, por un lado, a exaltar lo latinoamericano como una especie de alteridad radical que la desborda y la re-energetiza políticamente (tal como ocurrió con el boom del testimonio) y, por otro lado, a domesticar esa fuerza de alteridad sometiéndola a su control superior de lectura" (Richard, 2005). Por el contrario, sostiene la autora, la crítica latinoamericana de los EC busca revertir esa economía del sentido operando formas de descentramiento epistémico que permitan a la singularidad y diferencialidad latinoamericanas manifestarse teóricamente, con toda la fuerza heterogeneizante y desorganizadora de un 
contra-sistema que impida la clausura de su diferencia en una representación fija y controlada. En este sentido, Richard propone establece la meta de poder estatuir "no una diferencia diferenciada (representada o "hablada por"), sino una diferencia diferenciadora que tenga en sí misma la capacidad de modificar el sistema de codificación de las relaciones identidad-alteridad que busca seguir administrando el poder académico metropolitano" (Richard, 2005).

De acuerdo con Richard, uno de los primeros movimientos críticos que diseñaron los EC consistió en desbordar y rebasar el límite esteticista de los estudios literarios, cruzando lo simbólico-cultural con las expresiones masivas y cotidianas de los medios de comunicación. Los EC partieron del rechazo a la división jerárquica entre la cultura superior o letrada y los subgéneros de la cultura popular. Además de esta contaminación de fronteras entre lo culto y lo popular, lo simbólico y lo cotidiano, los EC sacaron la noción de texto del ámbito reservado y exclusivo de la literatura para extenderla a cualquier práctica social cuya articulación de mensajes resultara susceptible de ser analizada en términos de una teoría del discurso. Esta semiotización de lo cotidiano-social que borra la diferencia entre texto y discurso terminó desespecificando la categoría de lo literario en un contexto donde el protagonismo de la literatura -y el centralismo de su función, en América Latina, en los procesos de constitución imaginaria y simbólica de lo nacional había sido fuertemente desplazada por la hegemonía de los lenguajes audiovisuales y su imagen massmediática (Richard, 2005). La hipótesis de Richard es que la pérdida de centralidad de la literatura y de las humanidades como articuladoras de una relación entre ideología, poder y nación en el imaginario cultural y político latinoamericano, afecta también el lugar y la función de los intelectuales hasta ahora encargados de interpretar dicha relación. La crisis de lo literario sería entonces uno de los síntomas de la globalización massmediática que interpretan los EC al incluir dentro de su corpus de análisis aquellas producciones de consumo masivo que el mercado capitalista organiza y distribuye. El deseo de los EC de ampliar el "canon" de la institución literaria para introducir en ella producciones tradicionalmente desvalorizadas por inferiores, marginales o subalternas, contribuyó a disolver los contornos de lo estético en la masa de un sociologismo cultural, que se muestra ahora más interesado en el significado anti-hegemónico de las políticas minoritarias defendidas por estas producciones que en las maniobras textuales de su voluntad de forma (Richard, 2005). En este orden, Richard sostiene que la explicación sociologista a la que recurren los EC para abordar a la cultura en su dimensión de consumo sólo se encontraría capacitada para medir los efectos de producción y circulación social de los textos, pero no para atender lo más complejo de las apuestas estético-críticas que se libran en las estrategias de lenguaje y forma. Realzar el juego y la tensión de estas apuestas seguiría siendo una tarea necesaria que aún justifica la existencia de la crítica literaria, para que no triunfen los principios igualadores del mercado frente a los cuales los EC ofrecen muy poca resistencia.

Richard coincide en que los EC nacieron con la idea de mezclar la pluridisciplinariedad con la transculturalidad, en el sentido de lograr una apertura de las fronteras del conocimiento a problemáticas silenciadas por el paradigma monocultural de la razón occidental dominante. De este modo, los EC pretendían responder a los deslizamientos de categorías entre lo dominante 
y lo subalterno, lo central y lo periférico, lo global y lo local, que recorren las territorialidades geopolíticas, las representaciones sexuales y las clasificaciones sociales. Sin embargo, indica Richard, la transfronterización del conocimiento que inicialmente proyectaban se fue acomodando en una reposada suma de saberes pacíficamente integrados, conciliaciones prácticas entre saberes diferentes y complementarios que buscan extender y diversificar su comprensión de lo social y de lo cultural, pero sin que ninguna ruptura de tono ponga en cuestión la lengua técnica y operativa del intercambio de mensajes capitalista. En contrapartida con estos desarrollos, ella prefiere, para el caso latinoamericano hablar no de EC sino de Crítica Cultural: "La crítica cultural busca explorar los bordes de mayor disgregación institucional donde se formulan ciertas prácticas y estéticas 'menores' (en sentido deleuziano), cuyo registro de lectura -por inestable, por flotante, por desviado- no se aviene bien con las sólidas catalogaciones del saber eficiente que promueve el empirismo de los estudios culturales en su versión de conocimientos aplicados" (Richard, 2005).

En la misma línea de crítica hacia los EC en su versión heredada de Cultural Studies norteamericanos, Richard indica que los EC se definen por la extensividad de su nuevo modelo académico que se propone abarcarlo todo en términos de objetos: del texto vanguardista al videogame, de la ciudad benjaminiana al mall, de las marchas de derechos humanos a la performance artística, etcétera; y de métodos: todo sería combinable con todo (psicoanálisis, marxismo, deconstrucción, feminismo, etcétera).

En este sentido, si bien bajo el rótulo de EC hemos visto en las últimas dos décadas una producción muy variada, en cantidad y calidad temática, y si es verdad que como señala Richard una crítica seria al modelo académico de los EC latinoamericanos no puede soslayar el señalamiento de su pretensión de hacer de su objeto todo aquello que le pareciera de interés coyuntural fuera o no pertinente, por decirlo brevemente, un detalle de las líneas temáticas más desarrolladas podría ser presentada de la siguiente manera: una gran área de abordaje se ocupa de los procesos de globalización contemporáneos. Una segunda área se refiere al interés por los mecanismos de exclusión e inequidad y en el mismo orden, temas referidos a políticas culturales e industrias culturales en el cruce con el eje de la política y la ciudadanía global y local, asociado en los últimos años con el desarrollo acelerado de las TICs, Internet y redes sociales y sus aplicaciones. Cultura y desarrollo es una línea de estudio de interés creciente asociada a políticas culturales y a las construcciones identitarias. En los países del Cono Sur también se han profundizado los desarrollos en estudios de la memoria, sobre todo a partir de 2001 y a lo largo de toda la década. Finalmente, los debates propios de la teoría feminista y el indigenismo o desarrollos tales como estudios afrocaribeños o de pueblos originarios han incrementado en el último tiempo el arsenal teórico en debate.

Victor Silva Echeto intenta ya a cierta distancia de la llegada de los EC a América Latina alguna definición y un recuento histórico de manera más acotada y alejada del discurso celebratorio predominante. Silva Echeto señala que en América Latina, la tardía consolidación de las Ciencias Sociales, las Humanidades y las Artes lleva a encerrar los saberes y las prácticas, epistemológicamente, en disciplinas separadas, imposibilitando la consolidación de los EC. De este modo, en países como Brasil, Argentina y 
Uruguay van a ingresar lateralmente a los estudios literarios, antropológicos y de la comunicación, recién en los 80 cuando en Inglaterra ya existían desde los 60 . Echeto agrega que a esto hay que sumar la tardía incorporación en ciertos medios universitarios de teóricos, críticos y pensadores transversales con quienes dialogan los EC como Bajtin, Benjamin, Foucault, Derrida, Deleuze, Kristeva, Jameson, Haraway, etcétera (Silva Echeto, 2010: 83).

Silva Echeto indica que los EC se formulan a partir de los ejes ideología, política, poder y cultura; ejes que cuestionan los modos en los que estas mismas categorías eran analizadas en los años 60 y 70 en América Latina, a partir de una mezcla de marxismo, teoría del desarrollo, antiimperialismo, y, en algunos casos, con agregados muy particulares de interpretaciones de la Teoría Crítica (sobre todo de lecturas de las industrias culturales de Horkheimer y Adorno) y del althusserianismo. Según el autor en estas discusiones eran los estudios en comunicación (ALAIC) y los literarios (Rama y Rodríguez Monegal) los que hegemonizaban temas, lecturas e intereses.

Silva Echeto sostiene que nociones como hegemonía, desterritorialización del poder, violencia simbólica, poder simbólico, textos y discursos, significantes, identidades, diferencias culturales, género y feminismos, contracultura, cultura popular y cultura de masas, no ingresaban en las categorías predefinidas del saber instituido. En los 80 los EC entran por las líneas transversales y las fronteras de los estudios que mezclaban la comunicación, la literatura, la antropología y la sociología de la cultura (Silva Echeto, 2010: 84).

Su propuesta actual consiste en que los EC potencien la práctica transversal, el cruce archipiélago, los espacios entre e intersticiales que agujerean las fronteras de las disciplinas y coloquen brechas en el saber instituido. La transversalidad -transdisciplinaria-permite para él la apertura del conocimiento y la práctica de investigación; la toma de posición política y el compromiso crítico; la permanente alerta para analizar aquellos temas que emergen fluidamente, la desjerarquización de los saberes y la desterritorialización de las prácticas académicas (Silva Echeto, 2010: 86-87).

Junto a Browne Sartori, presentan una perspectiva disruptiva de los argumentos más conocidos en torno a EC. Ambos se reconocen como parte de la tradición latinoamericana que hizo estudios de la cultura antes de que los EC traspasaran el Atlántico y se redefinieran en nuestro continente vía EEUU. En el ámbito de las teorías de la comunicación, estos autores señalan que los EC originalmente intentaron superar la sociología funcionalista, criticando el modelo del emisor-canal-receptor o el del estímulo respuesta, incorporando el interés por las repercusiones ideológicas de los medios de comunicación y las respuestas dinámicas de las audiencias. Los conceptos claves, según ellos, para los estudios culturales y las teorías de la comunicación serán entonces los de identidad, identificaciones, interculturalidad, mercado, producción y consumo (Silva Echeto y Browne Sartori, 2007). La postura de Echeto y Sartori tiene que ver con sostener que "la comunicación no es una ciencia, ni una disciplina: más bien es indisciplinada" (2007: 117). Esta indisciplina estaría dada por la imposibilidad de identificar su origen y sólo reconocer sus huellas (por ejemplo, en la teoría matemática). Según estos autores la comunicación no legitima ningún proyecto epistemológico y su desterritorialización le permite escapar de los ámbitos propios del positivismo. 
"En tiempos de crisis y derrumbes teóricos, es necesario pensar desde la no ciencia, desde la no disciplina, desde el indisciplinamiento que habilita la no disciplina comunicación" (Silva Echeto y Browne Sartori, 2007: 128). En orden con este razonamiento, resulta imprescindible estudiar la comunicación desde un proceso de mixtura, de grietas e intersticios que se relacionan con el rizoma y la transversalidad. Su fundamento está dado por el carácter transversal, antidisciplinario e indisciplinado como inherente a la comunicación misma. Desde este punto de vista, la comunicación sería indefinible ya que su definición pasa por otros.

\section{EC y Comunicación en América Latina}

Néstor García Canclini es sin dudas, junto a Jesús Martín Barbero, uno de los referentes principales de los EC latinoamericanos y lo es por partida doble, también junto a Martín Barbero, en el campo de la Comunicación en nuestro continente. Sus posiciones respecto de qué entienden por Comunicación así como sus recorridos vitales y teóricos son bien distintos aunque sean contemporáneos y compartan esta especie de podio de fundadores del campo en la región.

Como bien señala Escosteguy (2002), en el caso de G...Canclini, se observa un desplazamiento en dirección a la importancia del mercado y su poder en la estructuración y constitución de las identidades. En este proceso, las industrias culturales sustituyen las interacciones directas por las mediatizaciones electrónicas. En este sentido, bajo la aparente convocatoria de la ciudadanía como contrapeso al impacto de las relaciones neoliberales de mercado, la resonancia de la propuesta parece convocar mucho más al consumidor que al ciudadano. En esa dirección, la crítica del autor se conecta con el proyecto de hegemonía cultural del mercado. Así, pasa a ser inevitable que la importancia asumida por el consumo en el contexto de configuración de identidades diversas, revele una convergencia teórica con las tesis de la Soberanía del consumidor y del Libre mercado (Escosteguy, 2002: 44).

En 1997, García Canclini indicaba que desde que comenzó a gestionarse el Tratado de Libre Comercio entre EEUU, México y Canadá, así como otros posteriores como el MERCOSUR o el Grupo de los Tres, no sólo liberalizaron el comercio, sino que concedieron espacio a cuestiones culturales, intercambios socioculturales a nivel multinacional y favorecieron actividades que antes no existían o eran débiles. Entre ellas menciona convenios entre empresas editoriales y de televisión, universidades y centros artísticos de diferentes países, nuevos programas educativos, científicos y artísticos de las naciones involucradas y sus alternativas de articulación entre los diferentes países. Según sus propias palabras, estaban cambiando las imágenes que cada sociedad tenía de las otras y las influencias recíprocas en los estilos de vida (García Canclini, 1997).

El aporte específico de los EC, de acuerdo con la posición de G.Canclini, tendría que ver con haber mejorado el conocimiento recíproco producto de los intercambios comunicacionales, económicos y migratorios entre EEUU y América Latina. De acuerdo con su postura, los EC lograron que se diferenciaran las diversas regiones y sectores y se superaran las definiciones difusas de las identidades nacionales. Al ofrecer visiones más profundas de la 
multiculturalidad y sus diferencias, de la desterritorialización y la reterritorialización, los EC permitieron retrabajar la información sobre la inconmensurabilidad ideológica entre las sociedades y sobre la americanización y la latinización (G. Canclini, 1997). Sin embargo, G. Canclini sostiene que no puede afirmarse que los EC constituyan un paradigma coherente y consistente. En su lugar, explica que ofrecen una narrativa, 0 varias en conflicto, con divergencias acerca del modo de estudiar la cultura y su relación con los contextos sociales:

"De acuerdo con la afirmación de Frederic Jameson de que los EC son menos 'una disciplina novedosa' que el intento de 'construir un bloque histórico', pueden interpretarse las contribuciones de esta corriente al intercambio de América Latina-EEUU como la narrativa más avanzada, con mejor elaboración crítica, pero aún dependiente de los proyectos socioculturales y políticos con que se tratan de encarar las contradicciones. Me refiero a las contradicciones entre lo local, lo nacional y lo global, entre el multiculturalismo hegemónico y el de las minorías en EEUU, entre las concepciones oficiales de la pluriculturalidad en América Latina y las posiciones de los sectores que no se sienten representados por ellas" (García Canclini, 1997: 49).

En este sentido G.Canclini advierte sobre la necesidad de trabajar sobre las divergencias teóricas y las inconsistencias epistemológicas que hacen que no pueda hablarse en los EC de modelos científicos sino de narrativas. En este orden presenta una propuesta que aspira a la universalidad del conocimiento y la búsqueda de una racionalidad interculturalmente compartida que dé coherencia a los enunciados básicos y los contraste empíricamente. Un primer requisito para alcanzar este modelo científico sería redefinir el objeto de los EC: de la identidad a la heterogeneidad y la hibridación multiculturales. Un segundo requisito tendría que ver con pensar los vínculos entre cultura, sociedad y saber en relación con las diferencias y con las desigualdades ${ }^{4}$. Finalmente, de acuerdo con el desplazamiento teórico sugerido (de la identidad a la heterogeneidad y la hibridación) los EC no deberían centrarse en las identidades parciales (metrópolis, naciones periféricas o poscoloniales, élites, grupos subalternos, disciplinas aisladas) sino ubicarse en las intersecciones. En este sentido, G. Canclini sugiere la posibilidad del uso de un solo punto de vista disciplinar en la etapa de descubrimiento, para generar hipótesis o contrahipótesis, pero, en el momento de la justificación epistemológica, desplazarse entre las intersecciones, en las zonas donde las narrativas se oponen y se cruzan, para elaborar conocimientos capaces de deconstruir y controlar los condicionamientos de cada enunciación. Su propuesta implicaría pasar de concebir los EC sólo como un análisis hermenéutico a entenderlos

\footnotetext{
${ }^{4}$ G. Canclini se desmarca de la noción marxiana de totalidad social al aclarar: "No estoy hablando de las nociones compactas de totalidad pseudouniversalistas y en realidad etnocéntricas, por ejemplo las hegelianas o marxistas, sino de las modalidades abiertas de interacción transnacional que propicia la globalización económica, política y cultural” (G. Canclini, 1997: 57). Para profundizar la discusión y leer una versión opuesta es interesante volver sobre (1998) Grüner, "Una introducción alegórica a Jameson y Zizek", En Estudios Culturales. Reflexiones sobre el multiculturalismo. Allí, Grüner señala que el problema no está en los fragmentos (lo cultural, lo social, el género, las identidades, etc.) sino en restituir las relaciones entre los fragmentos y la totalidad (en tanto modo de producción), una categoría cuya devaluación en abstracto es un síntoma de barbarie teórica e ideológica que aparece de manera mayoritaria en los EC (Grüner, 1998: 30).
} 
como un trabajo científico que combine la significación y los hechos, los discursos y sus garantías empíricas (García Canclini, 1997).

Jesús Martín Barbero, escribió en 1987 lo que fue luego quizás el libro más citado en las facultades de Comunicación de la región durante la década de los 90 (De los medios a las mediaciones). Considerado junto a G. Canclini el representante indiscutido de los EC en Latinoamérica, su posición teórica se distanció de la de aquél respecto de la cercanía al consumo y el mercado como principios laudatorios del consumidor=ciudadano, dándole mayor desarrollo teórico a los temas relacionados con la cultura, las mediaciones, lo urbano, los jóvenes. Sus preocupaciones centrales tuvieron que ver con la Comunicación y sus observaciones previas a De los medios... están relacionadas también con ese campo. Para fines de los 80 , principios de los 90, explica el auge de los EC en América Latina como algo que no tiene que ver exclusivamente con el mundo de la academia, sino que, señala, "no son únicamente los límites del modelo hegemónico los que nos han exigido cambiar de paradigma. Fueron los tercos hechos, los procesos sociales de América Latina, los que nos están cambiando el 'objeto' de estudio a los investigadores de comunicación [...] nueva fase en el desarrollo del capitalismo, en la que justamente el campo de la comunicación entra a jugar un papel decisivo" (Martín Barbero, 1991: 224).

La propuesta de M. Barbero consistió en aquellos años en dejar de pensar los procesos de comunicación desde las disciplinas que hasta ese momento se habían ocupado de la problemática (sociología, semiótica, teoría de la información) y desde los medios de comunicación para pasar a pensarlos desde la cultura. Para ese momento histórico, el autor vislumbraba una redefinición en el sentido de la cultura y en el de la política, donde la problemática de la comunicación importaba no solamente en relación a los intereses económicos que movían las empresas de comunicación. En la redefinición de la cultura resultaba clave para $\mathrm{M}$. Barbero la compresión de la naturaleza comunicativa, o sea, su carácter de proceso productor de significaciones y no sólo la circulación de informaciones, donde el receptor no era para él un mero decodificador de lo que el emisor ponía en el mensaje, sino un productor él también (M. Barbero, 1991: 228). Esta propuesta de M. Barbero, luego retomada y reproducida por muchos de los autores culturalistas latinoamericanos y hasta el hartazgo durante los 90 en trabajos con el sello de los EC en Comunicación, fue perdiendo la sustancia y la solidez iniciales para convertirse en un recurso fácil vaciado de contenido reconvertido con el rótulo de "receptor activo" al que pocos/as podrían reconstruirle su genealogía. En este sentido, podemos decir que tal vez lo más rico de De los medios... no sea la propuesta propiamente comunicacional/cultural sino el desarrollo teórico de la primera parte del libro donde $M$. Barbero se ocupa de explicar el redescubrimiento de la categoría de cultura popular y de retomar la obra de autores como Thompson, Williams y Hoggart. Especialmente en relación a la cuestión, largamente discutida, luego derivada en "el receptor activo", M. Barbero realiza un extenso desarrollo en torno de la categoría de hegemonía y de algunos conceptos gramscianos. No cabe duda en qué pensaba M. Barbero cuando imaginaba la posibilidad de un receptor negociador de sentidos. Es desde una matriz gramsciana, desde la idea de contrahegemonía y de pensar la relación emisor/receptor como un campo estratégico en la lucha por ser espacio articulador de los conflictos que lo está diciendo. 
Finalmente, su propuesta se centró en una doble ruptura que implicaba como punto de partida pensar la industria cultural desde la hegemonía. Una primera ruptura con el positivismo tecnologista que, según él entiende, reduce la comunicación a un tema de medios de comunicación, y con el etnocentrismo culturalista, que asimila la cultura de masa al problema de la degradación de la cultura. De este modo, M. Barbero reubicaba los problemas en el espacio de las relaciones entre prácticas culturales y movimientos sociales (M. Barbero, 1991: 95).

Para 2000, el autor se encuentra retrabajando el concepto de cultura y señala que el lugar de la cultura en la sociedad cambia cuando la mediación tecnológica de la comunicación deja de ser meramente instrumental para espesarse, densificarse y convertirse en estructural. Según Barbero, la tecnología remite no a unos aparatos sino a nuevos modos de percepción y de lenguaje, a nuevas sensibilidades y escrituras. "Lo que la trama comunicativa de la revolución tecnológica introduce en nuestras sociedades no es tanto una cantidad inusitada de nuevas máquinas sino un nuevo modo de relación entre los procesos simbólicos -que constituyen lo cultural- y las formas de producción y distribución de los bienes y servicios. El nuevo modo de producir, inextricablemente asociado a un nuevo modo de comunicar, convierte al conocimiento en una fuerza productiva directa" (M. Barbero, 2000). De este modo, la denominada sociedad de la información no es solamente aquella en la que la materia prima más costosa es el conocimiento sino también aquella en la que el desarrollo económico, social y político, se hallan estrechamente ligados a la innovación. M. Barbero indica que algunas consecuencias inmediatas de este proceso son por ejemplo un entorno educacional difuso y descentrado que ya no pasa exclusivamente por la escuela y ha ampliado su horizonte a los medios masivos y electrónicos; por otro lado, nuevas figuras de razón que interpelan a la tecnología inteligente ya que con la computadora no estamos ante una máquina con la que se producen objetos sino ante un nuevo tipo de tecnicidad que posibilita el procesamiento de informaciones y cuya materia prima son abstracciones y símbolos. Lo que inaugura una nueva aleación de cerebro e información que sustituye a la tradicional relación del cuerpo con la máquina. De otro lado, las redes informáticas al transformar nuestra relación con el espacio y el lugar movilizan figuras de un saber que escapa a la razón dualista con la que se estaba habituado a pensar la técnica durante la modernidad. Se trata de movimientos que son tanto de integración como de exclusión, de desterritorialización como de relocalización, nicho en el que interactúan y se entremezclan lógicas y temporalidades diversas ( $M$. Barbero, 2000).

Al hablar de la relación global/local, M. Barbero opina que es en este nuevo escenario donde la dinámica comunicativa de la cultura adquiere un rol fundamental. Al exponer cada cultura a las otras, tanto del mismo país como del mundo, los procesos de comunicación aceleran e intensifican el intercambio y la interacción entre culturas. Según M. Barbero, "poner a comunicar las culturas deja de significar la puesta en marcha de movimientos de propagación o divulgación para entrar a significar el diseño de políticas de activación de la experiencia creativa y la competencia comunicativa de cada comunidad cultural. La comunicación en el campo de la cultura deja de ser un movimiento exterior a los procesos culturales para convertirse en un movimiento entre 
culturas" (2000); es decir, de acceso, de apertura a las otras culturas, que implicará la transformación/recreación/ apropiación/invención de la propia.

Martín Barbero periodiza la construcción de los EC en América Latina en cuatro momentos: el de los cimientos, de 1930 a 1950, con tres representantes: el mexicano Alfonso Reyes, el cubano Fernando Ortíz y el peruano José Carlos Mariátegui. Un segundo momento, el de los procesos, de 1950 a 1970, conformado también por tres representantes. El historiador argentino José Luis Romero, Paulo Freire y su teoría de la dependencia y Ángel Rama y su idea de transculturación. El tercer momento es el de las prácticas y se corresponde con los últimos 20 años del siglo XX, donde la originalidad de América Latina está en poder pensar juntas la diferencia cultural, hoy transformada en diversidad 0 interculturalidad, y la desigualdad social (2010: 135-138).

En este marco, para inicios de los 80 , empiezan a cobrar relieve las prácticas culturales inmersas en mundos de vida diferentes (religiosos, estéticos, de consumo) y atravesadas por dimensiones que remiten a situaciones y escenarios económicos, políticos, sociales, cuyo estudio moviliza saberes y métodos de diversas disciplinas, y lenguajes expositivos diferentes. Es en ese doble cruce donde se va a insertar el estudio de las prácticas de comunicación, que desde los años 70 habían comenzado a ser focalizadas como un eje de análisis del lugar y el poder de los medios en la sociedad ya que en las prácticas emergían los sujetos de la comunicación y sus culturas:

"costumbres y fiestas religiosas, ritualidades profanas, aficiones y formas de entretenimiento, modos de oír la radio o ver la televisión. Son los 80 , la llamada 'década perdida', los años del mayor desarrollo de los grandes medios: expansión de la radio FM y primeras especializaciones de las emisoras, expansión del número de canales TV y crecimiento de las conexiones vía satélite, inicios de la televisión por cable acrecentado el tiempo de programación y empujando una demanda intensiva de programas que abrieron como nunca el mercado internacional a esa producción latinoamericana por excelencia: la telenovela. El espesamiento de la mediatización de la relación social y de la política vendrá a meter en el campo de la comunicación nuevas cuestiones como las de la memoria y las identidades, los nuevos movimientos de resistencia y reapropiación de las nuevas tecnologías que, si exigían nuevas herramientas para analizar la experiencia del mercado en rentabilizar la diferencia cultural también exigían cambios de fondo en los modos de estudio de los consumos y los usos sociales de los nuevos medios o de sus nuevas formas de presencia en la vida de la gente" (Martín Barbero, 2010: 139).

Un segundo momento de inflexión se da a principios de los 90 en un encuentro sobre EC en México. M. Barbero destaca dos notas distintivas de aquella etapa: por un lado, la fuerza y fecundidad de la lectura de género en las investigaciones norteamericanas ensanchando la idea y los actores de la dominación. Por el otro, el enlace que en América Latina tenía buena parte de la investigación con el diseño de políticas culturales tanto en el plano nacional como local; y ello ligado a la explicitación entre diferencia cultural y desigualdad social y a la necesidad de vincular lo cultural a los procesos de desarrollo: los procesos culturales en cuanto dinámicas de inclusión y cohesión social, de participación ciudadana y potenciación del capital cultural de las comunidades (2010: 141). 
La teórica brasilera Ana Escosteguy señala que recién en los 90 y de manera aislada unos pocos investigadores de América Latina comenzaron a identificarse o a ser identificados por otros autores con los EC. Escosteguy cita por caso a G. Canclini entre los primeros y a O'Connor, Fox y Lull entre los segundos. Por aquellos años la investigación en comunicación mostraba algunas modificaciones producto de desplazamientos internos al campo junto a movimientos más amplios de las ciencias sociales. En este sentido, el debate modernidad/posmodernidad, el horizonte marxista vigente hasta los 70 y la globalización eran los temas de discusión orientadores de la reflexión. La autora destaca el pasaje de un marxismo determinista a uno de corte gramsciano donde el sentido de la cultura como el de la política fueron redefinidos permitiendo repensar a las culturas populares y las identidades diversas. "La influencia gramsciana repercute en los desplazamientos que ocurren en los estudios en comunicación. A partir de los 80, el campo de la comunicación intenta seguir lo que está ocurriendo en los movimientos sociales y en la dinámica cultural más amplia, abriendo la investigación hacia las transformaciones de la experiencia social. Este tipo de análisis trae la marca de la multi/interdisciplinareidad o el sentimiento de que una única disciplina no da cuenta de la complejidad del momento en foco [...] el interés central es percibir las intersecciones entre las estructuras sociales y las formas y prácticas culturales. El análisis de los medios de comunicación en América Latina es visto en cuanto comunicación, pero en relación a la cultura y a los procesos políticos, como parte de la problemática del poder y la hegemonía" (Escosteguy, 2002: 38).

En su estudio Ana Escosteguy (2002: 39) identifica cuatro grandes áreas de análisis en el campo de la Comunicación a partir de los años 70 . Las tres primeras van desde 1970 hasta comienzos de los 80 y están impactadas por la teoría de la dependencia. Los temas allí reunidos son: influencia de la política económica internacional en el desarrollo cultural dependiente; políticas de los medios de comunicación y democratización de la comunicación y comunicación popular/alternativa como base para la democratización de la comunicación. La cuarta, trabajada a partir de mediados de los 80 y sobre la que se desarrollan sobre todo los EC, se centra en el papel de los medios masivos en la transformación de las culturas nacionales.

Escosteguy sostiene que la emergencia de nuevos actores, como movimientos sociales que llevaron adelante luchas contra la represión y la discriminación, movilizaciones de los sectores populares contra la apropiación de bienes y servicios, etcétera, politizaron asuntos considerados privados y permitieron la entrada en escena de intereses que extrapolaban el mundo del trabajo despertando otras dimensiones de la cultura. De este modo, la emergencia de estos nuevos actores puso en jaque a la cultura política tradicional renovando el ámbito de lo político. Junto a esto, Escosteguy señala que aunque la perspectiva de los EC en América Latina establezca relaciones con otras disciplinas como la historia o la literatura, el objetivo es demarcar sus diferencias en relación a la formación y constitución de otras trayectorias regionales. Los latinoamericanos intentan, en un primer momento, generar competencias pertinentes al cambio social. Es decir que tienen una tendencia socio política en los EC que aún persiste aunque atenuados (Escosteguy, 
2002: 40- 41). Esta posición será sostenida por otros teóricos/as y duramente criticada por quienes ven a los EC latinoamericanos y a los Cultural Studies norteamericanos como una distorsión de sus predecesores ingleses, sobre todo en lo que tiene que ver con su costado político y de crítica cultural. Precisamente, la pérdida de filo crítico y un fuerte proceso de despolitización son dos de las críticas más destacadas que los detractores de los EC les señalan.

Escosteguy, cierra su recorrido indicando que en el contexto latinoamericano, hacia 2000, puede observarse una atención creciente hacia la temática de las identidades y al papel ejercido por los medios de comunicación en su estructuración. La tendencia general que se esboza en los EC en el campo de la Comunicación aborda la constitución de identidades y representaciones donde el poder es entendido casi exclusivamente como una función de manipulación simbólica ${ }^{5}$. A partir de ese punto de vista, los diferentes grupos sociales y sus identidades pasan a ser vistos más como resultado del consumo simbólico, debilitándose los lazos con los procesos productivos. La noción de cultura, también se desprende de los procesos productivos y tiende a ser encarada estrictamente como simbólica (Escosteguy, 2002: 48)

Por su lado, la comunicóloga argentina Florencia Saintout señala que se produce un desplazamiento alrededor de la década del 80, de los medios o los instrumentos a la cultura, que permite a la comunicación correrse ("salirse", dice la autora) de la pregunta por lo que había sido su objeto prioritario, los medios masivos con sus efectos, para concentrarse en los modos de darle sentido a la vida de los actores sociales. Esta nueva pregunta se sitúa sobre una mirada específica que la liga a los procesos sociohistóricos de construcción de sentido, articulando comunicación, cultura y sociedad (Saintout, 2009: 146).

En su estudio Saintout explica que la mirada que liga a los EC con el campo de la comunicación en América Latina, habilita una nueva forma de abordar la comunicación que efectúa los siguientes movimientos:

-de la comunicación como asunto de instrumentos a la comunicación como cuestión de cultura; de luchas por la nominación del sentido legítimo del mundo; asunto de percepciones y sensibilidades

-de la comunicación como cuestión de poder a la comunicación como puesta en común; de la dominación como imposición a la dominación como proceso de comunicación

\footnotetext{
${ }^{5}$ Los estudios de recepción junto con los estudios de consumo cultural, configuran hasta 2000 el principal punto de desarrollo de los EC latinoamericanos. Existen diferentes abordajes: la perspectiva de los usos sociales de los medios, el enfoque integral de la audiencia, el trabajo desarrollado sobre el consumo cultural. Este tipo de estudios de recepción se detienen en la investigación empírica de la audiencia, sobre todo en la TV. A diferencia de lo que ocurrió en el contexto anglo americano, ese campo de investigación empírica no se desplazó de modo gradual desde análisis basados estrictamente en los textos hacia un enfoque más contextualista, es decir, análisis basados en el texto no fueron utilizados para mostrar el potencial de lecturas de resistencia o de oposición internas al mismo, construyendo el pasaje hacia la investigación del receptor y de allí hacia la importancia del contexto de la recepción. La adopción de la etnografía como principal estrategia metodológica en los estudios de recepción dirigió las investigaciones hacia un cierto énfasis descriptivo, privilegiando la evidencia empírica (Escosteguy, 2002: 44-46).
} 
-de la comunicación como problema exclusivamente de reproducción, de aparatos y estructuras, a la comunicación como cuestión también de producción y subjetividades

De este modo, la comunicación dejó de ser una cuestión de técnica, de medios como instrumentos, para transformarse en dimensión constitutiva de las prácticas sociales. Al mismo tiempo, la noción de cultura se entendió desde un desplazamiento o desbloqueo: no como mera reproducción, reflejo de las condiciones materiales de existencia, sino como producción y recreación social del sentido, como terreno donde se lucha por la hegemonía, por el poder nombrar legítimamente las visiones y divisiones del mundo (Saintout, 200: 147).

En el marco de estas transformaciones aparecen dos movimientos centrales: la crítica del poder conceptualizándolo como relación y no sólo como imposición dando lugar a la pregunta por la resistencia. Por otro lado, la crítica profunda al estructuralismo. Aquí la cultura se entiende como dimensión significante de lo social, como arena de lucha por los sentidos legítimos que una comunidad da al mundo en que vive. Tiene una doble dimensión: creación e innovación en las prácticas sociales; terreno de dominación y reproducción (Saintout, 2009: 147).

Saintout, como Mato, como Richard, como M. Barbero, señala que los EC arribaron a América Latina y se instalaron no sobre el vacío sino sobre una larga tradición de pensamiento sobre la relación cultura/sociedad. En su opinión esto hizo que si bien no pueden eludirse algunas críticas fuertes en algunos casos, tampoco pueden dejar de verse los lados promisorios que los EC tuvieron y tienen para la Comunicación y para las ciencias sociales. Entre las críticas que Saintout señala aparecen, por supuesto, el haber resultado funcionales a la producción y circulación de saberes en el neoliberalismo; el haber considerado, en general, a las desigualdades sólo como diferencias desprendidas de todo anclaje histórico y haber tomado la dimensión del poder desdibujada de toda constricción material. Esto en cuanto a lo político. En cuanto a lo científico, aparece la acusación de que los EC son sólo una moda sin reflexión epistemológica; el uso de la etnografía para toda situación; la carencia de investigación empírica, etcétera (Saintout, 2009: 148).

A medida que avanza la década del 90, de la mano de las fuertes transformaciones estructurales y de la influencia de la academia norteamericana, los EC van a ir asumiendo cada vez más una mirada "post" atenta a los desarrollos del mercado. En este contexto, el 2001 plantea nuevos desafíos para las agendas de investigación. En este sentido, Saintout indica que puede pensarse que a partir de ese momento algunos de los acuerdos que habían circulado con fuerza en el pensamiento social, y particularmente en el espacio de los EC, demandan un cuestionamiento, y que este sucede básicamente en torno de tres puntos:

-la hegemonía de las historias mínimas (el sujeto se ha desprendido de todo tipo de dimensión estructural). En contraposición, una nueva agenda tendrá que estar ligada a la problematización de los particularismos y sus articulaciones con las dimensiones estructurales del capitalismo tardío.

-el enflaquecimiento de la problematización del poder (ha dejado de ser demoníaco y material para ser fluido, ambulante, creativo y subjetivo. Hay un abandono de la dimensión de clase para el análisis y la comprensión de la 
cultura). En este sentido, la idea de microcapilaridad del poder ligada a su reubicación en la vida cotidiana y en su no exterioridad a la subjetividad fueron claves en el campo de la comunicación y los EC. Abrió posibilidades de investigación en temas como audiencias, nuevos movimientos sociales, reivindicaciones étnicas, de género, etcétera. Sin embargo, cada una de estas micro disidencias no fue pensada en articulación con otras luchas dentro del espacio social.

-celebración de la resistencia de los débiles en sí misma, lo que presupone el abandono de la subalternidad. Aceptación acrítica de que nuestras sociedades son sociedades de audiencias entendidas a partir de la lógica del consumo (Saintout, 2009: 149-151).

Saintout es clara respecto de la línea de tiempo trazada en la reconstrucción histórica del campo. Los 80 fueron los años de mayor riqueza y productividad. Luego de un momento de estudio de las culturas populares desde Gramsci, de Certau, Bajtin, Guizburg, resaltando la capacidad de invención y réplica de los sectores subalternos donde lo popular será comprendido como sujeto de producción de cultura, adviene la absorción de los efectos del modelo político económico del neoliberalismo y los EC y la comunicación reponen su objeto: la recepción. Se lleva cabo el desplazamiento de la pregunta política por la cultura de los sectores subalternos a la pregunta por la recepción, recepción desprendida de las condiciones estructurales. Van desapareciendo de la agenda las problemáticas de la subalternidad y la resistencia 0 la contrahegemonía. Los subalternos se trasforman en consumidores y la cultura popular se diluye en perspectivas que son utilizadas para pensar más en el consenso y la conciliación que los antagonismos y el conflicto (Saintout, 2009: 152).

\section{La recepción en la Argentina. Las voces de Grimson y Caggiano}

Los teóricos Grimson y Caggiano señalan que originarios de una carrera como Comunicación en un país como Argentina donde ese término no significa periodismo y en un contexto en el cual esa carrera fue la principal puerta de entrada para los Cultural Studies británicos, la teoría crítica y la propia sociología de la comunicación; los EC no fueron considerados una disciplina, ni una carrera, ni un departamento. "Históricamente, son una perspectiva teórica que construye nuevos objetos y modos de abordaje. Contemporáneamente, es un campo de convergencias de disciplinas y perspectivas teóricas, donde la propia politicidad se encuentra en cuestión" (Grimson y Caggiano, 2010: 17). Según ellos, la expansión a través de regiones e instituciones diversas hizo que el proyecto de los EC se diversificara y desdibujara límites y alcances. Sin embargo, y aquí coinciden con Martín Barbero, es dable reconocer algunos puntos constitutivos: en primer lugar, la politicidad de la cultura en clave de hegemonía. Esto significa colocar la pregunta acerca de las relaciones de poder en el centro de las preocupaciones por los modos en que los grupos sociales organizan simbólicamente la vida en común: valores, creencias, sentido de las prácticas. "En términos ontológicos, el poder no es sino ejercicio y relación. Retomando aportes foucaultianos, posmarxistas o ambos, los EC parten de concepciones 'no sustanciales' del poder y apuntan sus interrogantes hacia el ejercicio del poder en su carácter polimórfico y dinámico (Foucault, 
Laclau, Zizek). Se trata, en consecuencia, de poner el énfasis sobre las relaciones sociales en tanto que relaciones desniveladas" (Grimson y Caggiano, 2010: 18). En segundo lugar, el estatuto que lo que los autores denominan objetos menores adquieren como objetos de investigación científica o de reflexión intelectual articulando desde la cultura masiva y la cultura popular. En tercer lugar, la transdisciplinariedad como punto de partida de los proyectos de los EC o como horizonte hacia el cual dirigirlos.

Acerca de la tan mentada transdisciplinariedad, Grimson y Canggiano sostienen que ésta se construye desde cierta tradición. En Argentina la principal vertiente de los estudios de la cultura proviene de intelectuales formados en letras: Sarlo, Altamirano, Schmucler, Ford, etcétera, haciendo uso de herramientas metodológicas múltiples. En este marco, la transdisciplinariedad como construcción no es la sumatoria de tradiciones distintas, sino una combinatoria interpretativa útil y políticamente relevante. Se trata de un entretejido dificultoso, en el sentido de que exige eficiencia en campos muy diversos. En sus palabras: "Con la transdisciplinariedad como horizonte parece haber todo por ganar si se parte de asumir que esta presupone de alguna manera a las disciplinas" (Grimson y Caggiano, 2010: 25). En opinión de los autores, la transdisciplinariedad, como los EC la han promovido, resulta de conexiones y diálogos que procuran ser incomodantes y descolocadores, que provocan a las seguridades disciplinares y que pueden abrir las preguntas y renovarlas al confrontar la cortedad de la historia de las disciplinas con la historia general de los saberes, los fetichismos epistemológicos, teóricos y metodológicos a los que conducen muchas enseñanzas disciplinares que se muestran endebles. No obstante, los autores no dejan de señalar que el riesgo que se detecta en lo que parece ser la elaboración de proyectos pretendidamente transdisciplinares es que pueden desconocerse las tradiciones bibliográficas, los modos de formular problemas y de ensayar resoluciones que se han dado las disciplinas en sus historias respectivas. El resultado de esos proyectos es que no pueden aprovecharse los aportes de las disciplinas ni retar o hacer frente a las constricciones del disciplinamiento.

Grimson y Caggiano (2010: 28) señalan que los EC deberían lograr tornar sus problemas ya clásicos como lo popular, la diferencia o los medios, en los grandes problemas sociales, así como lograr que se abordara más sistemáticamente los grandes "problemas sociales": la pobreza, la economía, las crisis, la gran política, desde su propio punto de vista.

Grimson explica que se ubican como hijos de Birmingham y también de herederos latinoamericanos de los trabajos fundadores de Martín Barbero y de García Canclini. Al mismo tiempo, defienden sus opciones teóricas entendidas a partir de la opción por construir una caja de herramientas: caja muchas veces contradictoria, antagónica, "a la que vamos encontrándole la manera de maniobrar de acuerdo a lo que los propios objetos de estudio vayan necesitando o exigiendo. Nos interesa la deconstrucción, pero al mismo tiempo nos sigue interesando el marxismo, utilizamos la crítica postcolonial, y a la vez somos lectores de Lacan y todo eso intentamos leerlo desde la propia producción latinoamericana. En otras palabras, respecto a las herencias, es una herencia porosa, abierta, basada en la idea de que cada herramienta sirve 
para distintos objetos. Estamos muy lejos de una vieja noción de totalidad teórica, de un sistema cerrado" (Grimson y otros, 2010: 153).

Para estos autores la especificidad de los EC se centra en que es un proyecto contextual, lo que significa que se pregunta, en términos de lo concreto, por las relaciones constitutivas y por los amarres de lo cultural y lo político. En relación con esto, ese contextualismo se amarra con otro aspecto que diferencia a los EC y es que, tal como mostraba Barbero, operan desde lo concreto en el sentido gramsciano. No se imaginan como una acumulación de conocimientos abstractos y universales, como la acumulación de erudición, sino que su apuesta está en la transformación de relaciones de poder concretas. La teoría importa porque la teoría es fundamental para hacer intervenciones, incluso en la teoría misma (Grimson y otros, 2010: 154).

\section{Problemas de objeto. Algunas ideas sobre el final}

Muchos teóricos, entre ellos el argentino Roberto Follari (1999) sostienen que la particularidad específica de una disciplina como la Comunicación consiste en haberse establecido desde el campo profesional hacia el científico y no al revés (desde la especulación racional hacia las prácticas). Este hecho se suma a otras peculiaridades como por ejemplo el no haber un acuerdo al interior del campo respecto de la denominación del mismo. Se lo llama Ciencias de la Comunicación, Comunicología, Comunicación Social, Ciencias de la Información, etcétera, de acuerdo a cual sea el énfasis que se ponga o el interés que se tenga en determinados aspectos en discusión dentro de la disciplina.

Otro asunto de largo debate en estrecha relación con el anterior es el del objeto. Se ha dicho en repetidas ocasiones que la Comunicología trabaja sobre un objeto empírico propio pero desde los objetos teóricos de disciplinas diversas. Como señala Follari, desde este punto de vista, sería imposible hacer Comunicología autónoma, disociada de la explicación que sobre los procesos de interpretación, emisión, recepción, etcétera, se ofrece a partir de la sociología, la psicología o la lingüística. No habría autonomía disciplinar ya que el objeto no surge desde la constitución de un nuevo campo teórico, sino desde la directa necesidad social de explicarse un espacio concreto de funcionamiento de ámbitos de lo real (Follari, 1999).

Desde los iniciales estudios sobre los efectos de los medios de la mano de la teoría de Lasswell, pasando por toda la etapa de auge del funcionalismo y la Mass Communication Research, para llegar a la época de esplendor del estructuralismo en plenos 60, sin dejar de lado los estudios en teoría crítica basados en el legado de la Escuela de Frankfurt, el interés por los medios de comunicación fue una constante para los/as estudiosos/as de la Comunicación. Desde mi punto de vista, el meollo de la cuestión ha estado siempre allí y la variante ha estado en dónde se focalizaba la mirada, en qué costado de la relación: si en los emisores, si en los receptores, la producción, la circulación de mensajes, los contenidos, los textos, los discursos, los propietarios de los medios, y un largo etcétera que engloba cada vez de manera diferente el punto de vista que cada época le haya improntado: una perspectiva más cercana al positivismo, una perspectiva funcionalista, estudios críticos, un punto de vista 
gramsciano, althusseriano, estructuralista o ligado a un proyecto de carácter popular.

No obstante, existen otros/as autores/as que sostienen que el objeto de la comunicación, si aspira a ser una ciencia, debe ser o estar, en otro lado. Para algunos/as es un proceso, para otros/as las prácticas comunicacionales, hay quienes insisten por el lado de la cultura y quienes lo hacen por el lado de la indefinición de objeto en el sentido de que la especificidad de un objeto propio no sería indefectiblemente necesario, como tampoco lo serían las fronteras disciplinares.

Ante este estado de cosas, que no es nuevo sino, podríamos decir, casi constitutivo de la disciplina, no hay dudas de que la llegada, despliegue y florecimiento de los EC a América Latina tuvo el efecto de correr/desplazar el objeto de estudio o al menos la discusión en torno de éste, hacia la cultura y reemplazarlo por ésta. En este sentido, podría pensarse que la indefinición de recorte de objeto en Comunicación fue obturada por el auge de los EC, colaborando con el corrimiento del interés de la pregunta por los media hacia la cultura.

Para terminar esbozaré una propuesta de definición de objeto para la disciplina, propuesta que deberá seguir siendo profundizada y que está aún en ciernes.

Llegados a este punto considero que teniendo en cuenta las condiciones históricas ante las que nos encontramos como sociedad ${ }^{6}$, situación que como investigadores/as no podemos soslayar, se hace necesario revisar algunos postulados éticos en el marco de la academia. El conjunto de procesos sociales producidos en la región post 2001 y profundizados a lo largo de la primera década de 2000/2010 nos obligan a promover respuestas acordes a los nuevos fenómenos sociales pero desde un punto de vista situado (Haraway 1993), que se corresponda con nuestra historia, geografía, composición étnica, de género y de clase y que atienda nuestras realidades regionales. En este sentido, la visión del brasileño Luiz Martino, quien sostiene que la comunicación es ya una disciplina cuyo objeto de estudio son las nuevas prácticas comunicacionales me parece una perspectiva por la cual se podría seguir trabajando de una manera que yo articularía con una propuesta un poco más amplia. Para Martino, los medios de comunicación serían la expresión más constante y evidente del objeto de la Comunicación. El autor entiende que el campo es interdisciplinario ya que varias disciplinas contribuyen a la construcción de una disciplina con un objeto de estudio singular.

Coincido con Martino en que la mirada debe estar puesta en los medios masivos de comunicación y que dependiendo cómo se construya en cada caso el objeto podrá incluir también a los medios alternativos. Pero no será todo ni cualquier cosa estudiable desde o a través de los medios. El objeto de la Comunicación serán, desde la perspectiva que propongo, las prácticas comunicacionales desde los medios masivos y/o electrónicos y sus textos

\footnotetext{
${ }^{6}$ Dentro de la concepción de ciencia en la que propongo radicar la propuesta de objeto para la Comunicación, explicitar mi "situación" como investigadora resulta imprescindible: "situación" que deberá describir mi posición no sólo de clase, de género y de etnia sino también la más evidente de coordenadas de tiempo y espacio. Como se sabe y hemos podido revisar a lo largo de este estudio, no es neutral la posición de cada quien en la producción de conocimiento (Haraway, 1993).
} 
(gráficos, sonoros, visuales, audiovisuales, redes sociales, blogs, portales) desde un punto de vista situado. El objeto de la Comunicología serán, con mayor precisión entonces, los procesos y las prácticas comunicacionales y sus textos en los medios masivos y TICs en el marco de la función de transmisión y circulación de ideología que las industrias culturales poseen.

Esta propuesta es por ahora sólo una idea inicial en proceso de estudio e intenta recuperar desde una matriz gramsciana los aportes de la teoría crítica, la teoría situada de Haraway y la tradición de los estudios en Comunicación de la región.

\section{Bibliografía}

(2002) ESCOSTEGUY, Ana Carolina, "Estudios sobre las Culturas Contemporáneas”, Época II, V. VIII, № 15. Colima, p. 35-55.

(1999) FOLLARI, Roberto, "Comunicología latinoamericana: disciplina a la búsqueda de objeto”. En Fundamentos en Humanidades, № 1. Universidad Nacional de San Luis.

(1997) GARCIA CANCLINI, Néstor, "El malestar de los estudios culturales". Fractal, $\mathrm{N}^{\circ}$ 6, año 2, volumen II, p. 45-60.

(2010) GRIMSON, Alejandro y CAGGIANO, Sergio, "Respuestas a un Cuestionario: posiciones y situaciones". En En torno a los Estudios Culturales. Localidades, trayectorias, trayectorias y disputas, CLACSO, Buenos Aires.

(2010) GRIMSON, Alejandro y otros, Desde Lima: una conversación (inconclusa) sobre Estudios Culturales". En En torno a los Estudios Culturales. Localidades, trayectorias, trayectorias y disputas, CLACSO, Buenos Aires.

(1998) GRÜNER, Eduardo, “Una introducción alegórica a Jameson y Zizek”. En Estudios Culturales. Reflexiones sobre el multiculturalismo, Paidós, Buenos Aires.

(1993) HARAWAY, Donna, "Saberes situados: el problema de la ciencia en el feminismo y el privilegio de una mirada parcial". En Dubois y Cangiano (comp.), De mujer a género, CEAL, Buenos Aires.

(2010) MARTÍN BARBERO, Jesús, "Notas para hacer memoria de la investigación cultural en Latinoamérica". En En torno a los Estudios Culturales. Localidades, trayectorias, trayectorias y disputas, CLACSO, Buenos Aires.

(2000) MARTIN BARBERO, Jesús, “Culturas, Tecnicidades, Comunicación”. Revista Iberoamericana Pensar OEI, Guadalajara, México. Disponible en http://www.oei.es/cultura2/barbero.htm

(1991) MARTIN BARBERO, Jesús, De los medios a las mediaciones. Comunicación, Cultura y Hegemonía, Gili, México. 
(2001) MARTINO, Luiz, "Elementos para una epistemología de la comunicación". En Vasallo de Lopes, M. Immacolata y Fuentes Navarro, Raúl (comps.), Comunicación, campo y objeto de estudio, ITESO, Guadalajara, México.

(2002) MATO, Daniel, Estudios y otras prácticas intelectuales latinoamericanas en cultura y poder, CLACSO, Buenos Aires.

(2001) MATO, Daniel, "Introducción". En Cultura y transformaciones sociales en tiempos de globalización. CLACSO, Buenos Aires. Versión digitalizada.

(2010) RICHARD, Nelly (ed.), En torno a los Estudios Culturales. Localidades, trayectorias, trayectorias y disputas, CLACSO, Buenos Aires.

(2005) RICHARD, Nelly, "Globalización académica, estudios culturales y crítica latinoamericana". En Daniel Mato: Cultura, política y sociedad Perspectivas latinoamericanas. CLACSO, Buenos Aires.

(2009) SAINTOUT, Florencia, "Los estudios socioculturales y la comunicación: un mapa desplazado". Disponible en www.alaic.net/portal/revista/r89/art_07.pdf

(2010) SILVA ECHETO, Victor, "Respuestas a un Cuestionario: posiciones y situaciones". En En torno a los Estudios Culturales. Localidades, trayectorias, trayectorias y disputas. CLACSO, Buenos Aires.

(2007) SILVA ECHETO y BROWNE SARTORI, "Mirada crítica desde la comunicación a los estudios culturales". En Antropofagias. Las indisciplinas de la comunicación, Universidad Austral de Chile.

(2002) YUDICE, George, "Contrapunteo estadounidense/latinoamericano de los estudios culturales". En Daniel Mato (ed.) Estudios y Otras Prácticas Intelectuales Latinoamericanas en Cultura y Poder. CLACSO y CEAP, FACES, Universidad Central de Venezuela, Caracas. 